\title{
AUTONOMIA PROCRIATIVA: UM DIREITO FUNDAMENTAL DA MULHER? ${ }^{1}$
}

\author{
PROCRIATIVE AUTONOMY: A FUNDAMENTAL RIGHT OF WOMEN?
}

Isabela Leite IMADA²

Fábio Cantizani GOMES 3

ISSUE DOI: $10.21207 / 2675-0104.2019 .880$

\section{RESUMO}

A presente pesquisa almeja analisar a compatibilidade entre os artigos referentes ao aborto previstos no Código Penal de 1940 e os direitos fundamentais das mulheres previstos na Constituição Federal, como a dignidade da pessoa humana, a liberdade, a autonomia procriativa e a igualdade de gênero, relacionados com a laicidade do Estado. Dessa maneira, mediante essa análise do ordenamento jurídico brasileiro, o atual trabalho propõe-se a investigar qual seria a legislação sobre o procedimento abortivo ideal para a garantia dos direitos fundamentais das mulheres e a emancipação do controle masculino, visando combater a discriminação das mulheres e assegurar a autonomia sobre seu próprio corpo.

Palavras-chave: Aborto. Direitos fundamentais. Clandestinidade. Descriminalização.

\section{ABSTRACT}

The present research aims to analyze the compatibility between the articles referring to abortion foreseen in the Penal Code of 1940 and the fundamental rights of women foreseen in the Federal Constitution, such as the dignity of the human person, the liberty, the procreative autonomy and gender

\footnotetext{
${ }^{1} \mathrm{O}$ presente artigo sintetiza a monografia de conclusão da pesquisa, realizada para o Programa Interno de Bolsas de Iniciação Científica (PIBIC 2018-2019) da Faculdade de Direito de Franca (FDF), Franca/SP.

${ }^{2}$ Discente da Faculdade de Direito de Franca (FDF), Franca/SP. Bolsista do Programa Interno de Bolsas de Iniciação Científica (PIBIC 2018-2019).

${ }^{3}$ Doutorando em direito pela CEUB-ITE, Mestre e graduado pela UNESP - Franca/SP, professor de direito constitucional na Faculdade de Direito de Franca e na Universidade de Franca. Lattes: http://lattes.cnpq.br/7610232664441527. Contato: fabiocantizani@yahoo.com.br
} 
equality, related to the secularity of the State. Then, this research proposes an investigation regarding which would the best legislation conscerning the abortifacient procedure, for the guarantee of the women's fundamental rights and their body's emancipation from male's control, aiming to combat the women's discrimination and to assure their autonomy on their own body.

Keywords: Abortion. Fundamental rights. Clandestiny. Descriminalization.

\section{INTRODUÇÃO}

A presente pesquisa parte de uma irresignação para com a questão do aborto no ordenamento jurídico brasileiro atual, tendo como escopo estudar a questão da prática abortiva no país, analisando principalmente a compatibilidade existente entre os artigos que criminalizam o aborto do Código Penal e alguns direitos fundamentais previstos na Constituição Federal, como o direito à vida, a dignidade da pessoa humana, a autonomia, que compreende o direto à autodeterminação, a igualdade de gênero e ainda a liberdade de consciência e de crença.

Nesse seguimento, além de um estudo sobre o aborto no Brasil, destacando o tema no arcabouço jurídico vigente e no corpo social, o trabalho também explorará o contexto histórico que compreende a prática abortiva e alguns julgados de grande importância para a temática, como o HC 124.306 e a ADPF 442, atualmente em andamento no Supremo Tribunal Federal.

A questão do aborto é de suma importância, haja vista que a prática abortiva é um assunto extremamente polêmico e atual. Diversos países estão julgando a questão da criminalização, como o próprio Brasil, uma vez que está sendo discutida a constitucionalidade do aborto até a $12^{\mathrm{a}}$ semana de gestação no Supremo Tribunal Federal e a questão afeta sobremaneira a vida das mulheres que gostariam de realizar a interrupção voluntária de uma gestação.

Assim, o presente estudo também verificará as consequências que a legislação punitiva do aborto tem na vida das mulheres que vivenciaram e vivenciam a problemática. Nesse sentido, a presente pesquisa não tem como intuito discutir a moralidade do aborto, mas sim se as mulheres devem ser punidas e submetidas a procedimentos inseguros.

A principal metodologia utilizada foi a análise da jurisprudência sobre o tema e temáticas correlacionadas com o início da vida humana, essencialmente em julgados do Supremo Tribunal Federal, como a ADPF 54 que legalizou a antecipação terapêutica de fetos com anencefalia, o HC 
124.306 que tratou de um caso específico de uma clínica que realizava abortos e a ADPF 442, atualmente em andamento no Supremo Tribunal Constitucional, visando a descriminalização da interrupção voluntária da gravidez até a $12^{\mathrm{a}}$ semana gestacional.

Conjuntamente foi realizado um levantamento bibliográfico sobre a temática em obras doutrinárias, que além de fazerem uma análise sobre os julgados no que tange ao aborto, também disciplinam sobre a influência religiosa na temática, a importância de se aplicar a igualdade de gênero e ainda a dimensão moral, a argumentação jurídica, a dignidade humana e o pluralismo ideológico, enriquecendo o presente trabalho.

Também foram analisadas teses acadêmicas e artigos científicos, designando os conceitos de forma fundamentada para integrar o trabalho. Por fim, ainda foi realizado um estudo de dados concretos sobre o aborto no Brasil, em periódicos científicos e jornalísticos, base de dados governamentais, e também uma análise da Pesquisa Nacional do Aborto de $2016^{4}$, demonstrando dados e estatísticas acerca da prática abortiva no Brasil, contribuindo com a presente pesquisa.

Insta salientar ainda que, o método científico utilizado na presente pesquisa foi o dedutivo, posto que o trabalho partiu de uma análise geral de direitos e princípios constitucionais correlacionados com o aborto, chegando a um exame específico e singular de dois julgados de extrema importância para a temática, isto é, uma passagem do geral para o particular.

Nesse sentido, também foi utilizado o método histórico, ao se analisar a questão do aborto desde o Brasil Colônia até a atualidade, como consta no primeiro capítulo da presente pesquisa.

Diante de todo o exposto, busca-se elaborar um estudo sobre a criminalização do aborto no Brasil, apontando os impactos no corpo social e realizando uma discussão sobre a possibilidade de alteração dessa matéria no Código Penal. Outro objetivo da presente pesquisa foi realizar uma reflexão sobre as contradições que os próprios artigos sobre o aborto (arts. 124 ao 128 do Código Penal) apresentam no tocante à Constituição Federal e ainda estudar a possibilidade de inserir um aborto seguro no ordenamento jurídico brasileiro em prol da autonomia sexual e reprodutiva da mulher.

${ }^{4}$ Pesquisa Nacional de Aborto 2016. Disponível em: http://www.scielo.br/scielo.php?pid=S141381232017000200653\&script=sci_abstract\&tlng=pt. Acesso em: 05.05.2019. 


\title{
2 O ABORTO E SUA EVOLUÇÃO HISTÓRICA
}

A palavra aborto vem do latim $a b$ ortus e significa privação do nascimento, assim, diante da não conceituação do aborto pelo ordenamento jurídico brasileiro, coube a doutrina conceituar, essa em sua maioria entende que aborto é a interrupção da gravidez que põe fim ao desenvolvimento do feto, nesse sentido, entende o Cezar Roberto Bitencourt:

\begin{abstract}
A ação de provocar o aborto tem a finalidade de interromper a gravidez e eliminar o produto da concepção. Ela se exerce sobre a gestante ou também sobre o próprio feto ou embrião. E só há crime quando o aborto é provocado; se é espontâneo, não existe crime. Se os peritos não podem afirmar, por exemplo, que o aborto foi provocado, não há certeza da existência de crime, e sem tal certeza não se pode falar em aborto criminoso. ${ }^{5}$
\end{abstract}

Conjuntamente a isso, vale ressaltar ainda que somente é considerado um aborto os casos de gestações convencionais, dessa maneira as gestações que ocorrem nas trompas, na parede do útero, no ovário, isto é, gestações extrauterinas e também a gravidez molar não se enquadram na conceituação de aborto, uma vez que esse feto não teria condições de se desenvolver normalmente.

O aborto pode ser dividido em diversas espécies, algumas delas criminalizadas (aborto provocado) e outras não (aborto espontâneo e acidental).

Vale ressaltar ainda mais algumas espécies de abortamentos, o aborto necessário é aquele que ocorre em consequência do risco de vida para a mãe, conforme entendimento do Nelson Hungria essa espécie de aborto é ".. a interrupção artificial da gravidez para conjurar perigo certo e inevitável por outro modo, à vida da gestante...". ${ }^{6}$ previsto e legalizado no art. 128, inciso I do Código Penal de 1940, sendo a primeira legislação brasileira à assegurar esse direito às mulheres. Tal dispositivo teve como intuito, diante do dilema entre a vida do feto e da mulher, proteger e salvaguardar a vida da mulher.

Já o aborto sentimental, é aquele permitido também pelo ordenamento jurídico brasileiro no art. 128, inciso II do Código Penal, esse

\footnotetext{
${ }^{5}$ BITENCOURT, Cezar Roberto. Tratado de direito penal, 2: parte especial: dos crimes contra a pessoa.12. ed. rev. e ampl. São Paulo: Saraiva, 2012. p. 397

${ }^{6}$ HUNGRIA, Nélson. Comentários ao Código Penal. Volume 5. 4. ed. Rio de Janeiro: Forense 1958, p. 312
} 
ocorre no caso da mulher ser vítima de estupro, demonstrando assim, que uma mulher não deve ser obrigada a manter uma gestação fruto de uma violência.

Por fim, tem-se o aborto eugênico ou eugenésico que ocorre quando o feto irá nascer com alguma patologia ou deformidade, divergindo dos padrões sociais, aqui não se trata da antecipação terapêutica em casos de fetos anencéfalos. Cumpre registrar ainda que tal espécie com o fim de purificar a raça ariana, foi utilizada pelos nazistas de Hitler contra os judeus.

Ademais a isso, quanto ao contexto histórico brasileiro no tocante à prática abortiva, tem-se que nem sempre o aborto foi proibido e criminalizado no país, tal procedimento só foi disciplinado no Código Criminal do Império de 1830 (arts. 199 e 200), no entanto, a legislação vigente não punia o auto-aborto, isto é, quando a própria gestante realizava o aborto em si mesma, assim a prática abortiva só era considerada crime quando praticada por terceiros, independentemente do consentimento da gestante.

Em face da omissão no tocante a ilegalidade do auto-aborto, resta-se claro que a lei que criminalizava o aborto na época, não visava proteger o feto, mas sim a mulher, como se diz o título do capítulo, a segurança da pessoa ("Capítulo I - Dos crimes contra a segurança da pessoa, e vida").

Nesse diapasão, somente após o século XIX, em que o Brasil passou a ser uma República, o auto-aborto passou a ser criminalizado, no "Título X- Dos Crimes Contra a Segurança da Pessoa e Vida", estando presente no ordenamento jurídico brasileiro até os dias de hoje, praticamente inalterado, tal legislação da República, além de criminalizar a conduta da gestante que pratica o aborto, também incluiu uma atenuante para essas mulheres que realizassem a prática abortiva com o intuito de ocultar desonra própria, e ainda resguardou o direito ao aborto legal ou necessário, que é aquele realizado para salvar a vida da gestante.

Dessa maneira, é notório como o bem jurídico ainda não era a vida do feto, mas nesse caso, a honra da gestante. Vale ressaltar também que essa legislação penal surgiu em um momento em que chegaram os ideais liberais ao país, e também se mantinha o machismo, o patriarcalismo e ideais conservadores.

Nessa senda, surgiu o Código Penal de 1940, que tipificou a prática abortiva em seus arts. 124, 125, 126, 127 e 128. O primeiro deles, 
se trata do abortamento praticado pela própria gestante ou com o seu consentimento, tendo como pena, detenção de um a três anos. Já o art. 125, criminaliza o procedimento quando praticado por um terceiro, sem o consentimento da gestante, punindo o sujeito ativo com reclusão de três a dez anos. $\mathrm{O}$ art. 126, também se refere ao aborto praticado por um terceiro, mas dessa vez, com o consentimento da gestante, tendo uma pena menor, reclusão de um a quatro anos. $\mathrm{O}$ art. 127 descreve duas formas qualificadas, quando ocorre a lesão grave ou a morte da mulher. E o art. 128 descreve duas condutas praticadas por um médico que não são punidas, entre elas quando há risco de vida para a mulher (aborto necessário) e a outra em caso de estupro (aborto sentimental).

É notório como o bem jurídico não mais é a honra da mulher e como demonstra o próprio Código Penal no título e capítulo "Título I- Dos crimes contra a pessoa" e "Capítulo I- Dos crimes contra a vida", o bem jurídico tutelado é a vida potencial do feto.

Ademais a essas duas excludentes de ilicitude do Código Penal, o Supremo Tribunal Federal, no julgamento da Arguição de Descumprimento de Preceito Fundamental 54, decidiu que a antecipação terapêutica de fetos anencéfalos é constitucional, uma vez que nenhuma mulher deveria ser obrigada a levar a termo uma gestação de um feto que não desenvolverá qualquer função superior do sistema nervoso central, estando fadado a morte, ocasionando, assim, à mulher inúmeros danos psíquicos e físicos.

Portanto, o ordenamento jurídico brasileiro tipifica o aborto em seus arts. 124, 125, 126 e 127, e o art. 128 estabelece que são permitidos o aborto sentimental (fruto de estupro) e o aborto necessário (quando há risco de vida para a mãe), nesse sentido, o Supremo Tribunal Federal também legalizou a conduta da antecipação terapêutica de fetos anencefálicos no julgamento da Arguição de Descumprimento de Preceito Fundamental $n^{\circ}$ 54. 


\subsection{AS RELAÇÕES ENTRE O ABORTO, O DIREITO À VIDA E O PRINCÍPIO DA DIGNIDADE DA PESSOA HUMANA}

A questão do aborto é de extrema polêmica pois está intrinsecamente relacionada com o direito à vida, direito este que é o bem jurídico de maior valor para o ordenamento jurídico brasileiro.

Uma das grandes complexidades no tocante a vida se dá quanto ao seu início, uma vez que, quanto ao fim, resta-se claro, conforme disciplina a Lei de Transplante de Órgãos (Lei 9.434/97), que a vida cessa com a morte encefálica, isto é, quando se encerram as atividades do encéfalo que é o cerne do sistema nervoso é considerado o momento em que não há mais vida, posto que a morte encefálica é irreversível e não há mais nada que os médicos possam fazer, até mesmo a manutenção das atividades cardíacas e pulmonares mediante aparelhos são inúteis.

O principal obstáculo para se alcançar um consenso acerca do início da vida humana se dá porque essa matéria transcende o direito, e é de grande importância também para diversas ciências, assim, na tentativa de se alcançar um conceito unânime, foram criadas diversas teorias, entre elas quatro são de maior destaque: a teoria concepcionista (que defende que a vida se inicia na concepção), a teoria da nidação (que argumenta que a vida tem seu início na nidação), a teoria do desenvolvimento do sistema nervoso central (que alega que a vida se inicia com o desenvolvimento do sistema nervoso central) e a natalista (que entende que a vida tem seu início com o nascimento).

$\mathrm{O}$ direito à vida é garantido pela Constituição Federal, em seu art. $5^{\circ}$, caput e este, conforme afirma o constitucionalista André Ramos Tavares, é um princípio basilar que norteia e sustenta diversos outros direitos garantidos pela Magna Carta: "o mais básico de todos os direitos, no sentido de que surge como verdadeiro pré-requisito da existência dos demais direitos consagrados constitucionalmente. É, por isto, o direito humano mais sagrado"?

Ademais, o direito à vida está intrinsecamente relacionado com o direito à dignidade humana, posto que de nada adiantaria garantir à pessoa humana o direito à vida, sem que essa fosse adequada e digna.

\footnotetext{
7 TAVARES, André Ramos. Curso de Direito Constitucional. 8. ed. São Paulo: Editora Saraiva, 2010, p. 569.
} 
Por essa razão, será analisado também nesse capítulo o princípio da dignidade da pessoa humana, estabelecido no art. $1^{\circ}$, inciso III da Constituição Federal de 1988.

O princípio da dignidade da pessoa humana está intimamente relacionado com o entendimento kantiano de que a pessoa deve ser considerada um fim em si mesma, e não ser utilizada como meio para algo, isto é, uma instrumentalização, ou coisificação da pessoa.

A dignidade coloca a pessoa no centro do direito e ainda assegura ao ser humano o direito de ser respeitado por todos e também o direito a autonomia, conforme entendimento do Ministro Luís Roberto Barroso:

A dignidade, na visão kantiana, tem por fundamento a autonomia. Em um mundo no qual todos pautem a sua conduta pelo imperativo categórico - no "'reino dos fins"", como escreveu -, tudo tem um preço ou uma dignidade. As coisas que têm preço podem ser substituídas por outras equivalentes. Mas quando uma coisa está acima de todo o preço, e não pode ser substituída por outra equivalente, ela tem dignidade. Tal é a situação singular da pessoa humana. Portanto, as coisas têm preço, mas as pessoas têm dignidade. $^{8}$

Nesse seguimento, a questão do aborto é extremamente polêmica, de um lado os defensores da descriminalização afirmam que obrigar a mulher a manter a termo uma gestação indesejada fere sua dignidade e autodeterminação e do outro, os contrários à prática abortiva sustentam que o aborto viola o direito à vida do feto. Desse modo para decidir a presente questão, deve-se realizar um sopesamento entre esses princípios constitucionais.

Como visto acima, as ciências biológicas ainda não definiram exatamente quando se inicia a vida, demonstrando que não há uma unanimidade acerca da existência ou não de vida do feto. Nesse diapasão, deve-se analisar a razoabilidade e a proporcionalidade das correntes supracitadas. Por esse motivo a posição adotada pelo presente trabalho é a teoria do desenvolvimento do sistema nervoso central, que apesar de não possuir um marco exato, não constitui direito à vida ao embrião desde a concepção ou então desde a nidação.

\footnotetext{
8 BARROSO, Luís Roberto. A dignidade da pessoa humana no direito constitucional contemporâneo: natureza jurídica, conteúdos mínimos e critérios de aplicação. Disponível em: https://www.luisrobertobarroso.com.br/wp-content/uploads/2010/12/Dignidade_textobase_11dez2010.pdf. Acesso em: 13.05.2019. p 17
} 
Por esse motivo, considerando que até a formação do sistema nervoso central o nascituro não possui vida, a dignidade humana da mulher deve prevalecer na questão do aborto até a $12^{\mathrm{a}}$ semana de gestação, uma vez que a criminalização afeta diretamente sua vida, tendo essa que modificar seus planos e muitas vezes abdicar de seus sonhos.

Isto posto, a criminalização da prática abortiva não reduz os índices de abortamentos, tendo em vista que quase uma em cada cinco mulheres até 40 anos já realizou o procedimento, como demonstra a Pesquisa Nacional do Aborto. ${ }^{9}$ Além disso, a criminalização causa diversos danos na vida da gestante, tendo em vista que os procedimentos clandestinos e precários submetem às mulheres a grandes riscos, como perfurações do útero, infecções e até a morte materna, violando diretamente sua dignidade humana e consequentemente seu direito à vida e a autodeterminação, enquanto nem ao menos é certo se há vida no feto, demonstrando que a dignidade da mulher deve sim prevalecer sobre o feto no que $\mathrm{c}$ oncerne ao aborto nas primeiras semanas de gestação.

\subsection{O GÊNERO COMO CONDENAÇÃO: O ABORTO E O PRINCÍPIO DA IGUALDADE DE GÊNERO}

$\mathrm{O}$ princípio da igualdade de gênero disciplina que todos os homens e mulheres devem ser tratados igualmente, conforme estabelece o art. $5^{\circ}$, inciso I da Magna Carta.

A partir do texto constitucional, nota-se a necessidade de uma efetiva igualdade entre os homens e as mulheres, nesse sentido o ordenamento jurídico deveria impedir todas as formas de discriminação para com as mulheres, como entende Castilho:

A principal solução para que se alcance a igualdade de gênero é jurídica. As legislações nacionais devem cuidar para que os direitos acordados na Convenção sobre a Eliminação de Todas as Formas de Discriminação contra as Mulheres sejam inseridos em todos os âmbitos, seja social, político ou de trabalho. Este é o caminho inicial para que se destruam os estereótipos negativos. Com a lei será possível dar início ao processo de eliminação da violência contra as mulheres: pobreza, falta de educação, precariedade de

\footnotetext{
${ }^{9}$ Pesquisa Nacional de Aborto 2016. Disponível em: http://www.scielo.br/scielo.php?pid=S1413$81232017000200653 \&$ script=sci_abstract\&tlng=pt. Acesso em: 05.05.2019.
} 
atendimento de saúde, uso da mulher em conflitos armados e alienação da mulher dos cargos de poder e dos meios de comunicação. ${ }^{10}$

É evidente que existem diferenças biológicas entre homens e mulheres, como o sistema reprodutivo e os hormônios, prova disso é a capacidade da mulher de gerar outro ser através de uma gestação. No entanto essas divergências não devem desencadear desvantagens econômicas e oportunidades sociais desiguais na vida das mulheres. Tais características próprias da natureza não podem prejudicá-las, seja no trabalho, no social e até na possibilidade de ter autonomia sobre seu próprio corpo, devendo-se aplicar em todos os aspectos a igualdade de gênero.

Nesse sentido, não há como analisar a situação do aborto no Brasil em apartado com as desigualdades de gênero que ocorrem simultaneamente, a criminalização da prática abortiva é inclusive uma maneira de se predestinar as mulheres à maternidade e mantê-las dominadas pelos homens, figurando no papel de mãe, mulher e dona de casa, conforme entende a estudiosa Teresinha Inês Teles Pires:

\begin{abstract}
A proibição do aborto parte da presunção de que as mulheres estão predestinadas ao desempenho da função de criar os filhos, sendo que a mesma obrigação não é imposta aos homens. Via de consequência, as restrições ao acesso seguro ao aborto, calcadas no estabelecimento de papéis familiares, convencionalmente firmados em uma perspectiva de gênero, acarreta a consideração do homem e da mulher como cidadãos pertencentes a esferas sociais estanques, o que contraria a base igualitária dos sistemas constitucionais do nosso tempo. ${ }^{11}$
\end{abstract}

Enquanto o patriarcado submete às mulheres à maternidade compulsória, a igualdade de gênero estabelece que homens e mulheres devem ser tratados igualmente, não cabendo às mulheres o destino da maternidade, como preceitua Letícia Kreuz:

O patriarcado impõe o mito da maternidade, sem o qual as mulheres poderiam questionar a obrigação de ter filhos e, com isso, mudar o sentido de suas vidas - sair da lógica meramente maternal. As mulheres são vistas enquanto "reprodutoras de herdeiros", pois o patriarcado impõe o controle da sexualidade e, por conseguinte, da capacidade reprodutiva da mulher. $\mathrm{O}$ feminino é confundido com o materno e restrito ao corpo. Nessa lógica, o aborto é um tabu, uma

\footnotetext{
${ }^{10}$ CASTILHO, Ricardo. Direitos humanos. 5. ed. São Paulo: Saraiva, 2015. p. 369

${ }^{11}$ TELES, Teresinha Inês. Direito ao aborto, democracia e constituição. Curitiba: Juruá, 2016. p. 104
} 
"metáfora para a mãe desnaturada, aquela que não quis obedecer à "natureza"” ${ }^{81}$ Há uma inversão ideológica, citada anteriormente, que faz parecer ser da mulher a violência praticada, graças ao "desnaturamento" da ideia de maternidade. ${ }^{12}$

Por todo o exposto, nota-se que os estudiosos vêm entendendo que a criminalização do aborto afronta diretamente a igualdade de gênero, uma vez que é imposto às mulheres, decisões pautadas em uma cultura patriarcal que impede o exercício da autonomia pela mulher e viola sua dignidade humana.

\subsection{A INFLUÊNCIA DOS DOGMAS RELIGIOSOS SOBRE A} AUTONOMIA PROCRIATIVA: A QUESTÃO DO PRINCÍPIO DA LIBERDADE DE CONSCIÊNCIA E DE CRENÇA

No tocante a relação com a religião, um Estado pode ser confessional, teocrático, laico e ateu. O primeiro deles trata as religiões com igualdade, todavia protege uma, isto é, possui um vínculo maior com determinada religião. Já o Estado teocrático, que é um desdobramento do confessional, apresenta uma ligação total com uma religião, inclusive há uma confusão entre Estado e Deus. Por sua vez, o Estado laico é aquele que propõe a separação total entre Estado e Igreja, respeitando de forma igualitária todas as religiões. Por fim, o Estado ateu persegue as religiões, partindo da premissa de que essas alienam o homem.

Nesse jaez, no que se refere a essa classificação explicitada acima, o Brasil se tornou laico desde a Constituição de 1891, abolindo o Estado confessional do Império, como estabelece seu art. $72, \$ 3^{\circ}$.

Desde então, o Brasil é considerado um Estado laico, conforme se disciplina a atual Constituição Federal, garantindo a liberdade de consciência e de crença e também a separação entre Estado e Igreja.

Logo, a Administração Pública deveria se pautar na laicidade, nesse sentido, Luís Roberto Barroso defende que "na política e nos assuntos públicos, uma visão racional e humanista deve prevalecer sobre concepções religiosas." "13. Contudo, na prática ainda há uma certa confusão

\footnotetext{
${ }^{12}$ KREUZ, Letícia Regina Camargo. Domínio do corpo: O aborto entre leis e juízes. Curitiba: Íthala, 2018. p. 31

${ }^{13}$ KREUZ, Letícia Regina Camargo. Op. cit. p. 64
} 
entre Estado e religião, exemplo disso é a própria Constituição que invoca a proteção de deus em seu preâmbulo, a atuação da bancada evangélica no Congresso Nacional, a adoção de feriados católicos e a utilização de símbolos religiosos em prédios públicos, conforme leciona Letícia Kreuz:

A influência religiosa no Brasil é inegável. Laico formalmente desde 1890, o país sofre, ainda hoje, com elementos cristãos em órgãos públicos (a exemplo dos crucifixos) e com a constante interferência de discursos de cunho religioso, católico, protestante e evangélico, em questões políticas, a exemplo das corridas presidenciais, em que os candidatos que aparecem com reais chances de eleição nas pesquisas evitam entrar em determinados temas por temer a reação dos grupos religiosos. O aborto permanece um tabu nesse cenário. ${ }^{14}$

No que concerne ao aborto, a laicidade é de extrema importância, uma vez que, a prática abortiva é considerada um pecado pelos cristãos, inclusive pela Igreja Católica, até os dias atuais, como preceitua Letícia Kreuz:

Este é o ponto central. É apenas a partir da laicidade estatal que se pode pensar em determinados direitos, a exemplo dos direitos reprodutivos da mulher, aí inseridos a pílula anticoncepcional, a pílula do dia seguinte, o DIU, os preservativos descartáveis e, especialmente, a interrupção voluntária da gestação. Todas essas hipóteses são condenadas pela Igreja Católica atualmente - e por cristãos evangélicos. Até mesmo o planejamento familiar é questionado, sob a ótica de que a "família cristã" deve ter "tantos filhos quantos Deus os confiar", não tantos filhos quantos sua condição econômica permita ou quantos tenham vontade. A ideia é que "Deus manda" o filho, não o casal decide, racionalmente, pela paternidade. ${ }^{15}$

Assim, sendo o Brasil um Estado laico, influências religiosas não devem se sobrepor ao Estado Democrático de Direito. Da mesma maneira que o Estado permite as pessoas professarem suas crenças, essas não podem impor seus posicionamentos à toda sociedade, ainda que de religiões majoritárias. Portanto, ao discutir sobre o aborto deve haver uma emancipação da temática para com argumentos religiosos, pois estes não se adequam à Constituição Federal, à laicidade e ao Estado Democrático de Direito.

\footnotetext{
${ }^{14}$ KREUZ, Letícia Regina Camargo. Op. cit. p. 61

${ }^{15}$ KREUZ, Letícia Regina Camargo. Op. cit. p. 69.
} 


\section{ANÁLISE DE JULGAMENTOS QUE IMPACTARAM O ABORTO NO BRASIL}

\subsection{HABEAS CORPUS N. 124.306: CRIAÇÃO DE PRECEDENTE NA ANÁLISE DE UM JULGAMENTO INTER PARTES}

Nesse ponto, será realizada uma análise do Habeas Corpus $n^{\circ}$ 124.306, julgado pelo Supremo Tribunal Federal, acerca do cerceamento da liberdade dos pacientes Rosemere Aparecida Ferreira e Edilson dos Santos.

A princípio, houve uma denúncia anônima às autoridades de que havia uma clínica clandestina realizando abortos no Bairro do Xerém no Rio de Janeiro. Por esse motivo, a polícia ao verificar o funcionamento dessa clínica prendeu em flagrante vários envolvidos no crime, inclusive Rosemere e Edilson, pacientes do processo em questão, respectivamente, a chefe da quadrilha e quem auxiliava no transporte das gestantes ao local da realização do procedimento. ${ }^{16}$

A prática funcionava da seguinte forma: via ligação telefônica, era combinado o valor do procedimento, o horário e a data a ser realizado, assim como o encontro em frente ao estabelecimento comercial "Casa e Vídeo", desse modo a denunciada Débora, também envolvida na quadrilha, encontrava as gestantes no local previamente combinado e encaminhava para um veículo algumas vezes conduzido pelo denunciado Edilson, ou então o taxista Jadir Messias da Silva, para o transporte até a clínica. Assim sendo, o médico, também denunciado, Carlos Eduardo de Souza Pinto, realizava o procedimento abortivo com o consentimento da gestante, e após o devido pagamento anteriormente pactuado, a quadrilha levava a paciente de volta ao ponto de encontro. ${ }^{17}$

Dessa maneira funcionava a clínica, até abordagem policial, em que Edilson assumiu a direção de um veículo a fim de fugir junto com seus comparsas, bem como com algumas gestantes. Nesse momento, na clínica, foi encontrada uma gestante na mesa ginecológica com grave sangramento,

\footnotetext{
${ }^{16}$ BRASIL. Supremo Tribunal Federal. Habeas Corpus 124.306 Rio de Janeiro. Pág. 33. Disponível em: http://www.stf.jus.br/arquivo/cms/noticiaNoticiaStf/anexo/HC124306LRB.pdf. Acesso em: 28 de out. 2018

${ }^{17}$ Idem
} 
por essa razão ao encontrarem os envolvidos na empreitada criminosa, os policiais impuseram que o médico retornasse à clínica para estancar o sangramento.

Em virtude desses fatos, foram denunciados todos os envolvidos em 21 de março de 2013, e ainda o Ministério Público, órgão da acusação, solicitou a transformação da prisão em flagrante em preventiva. Todavia, o magistrado competente da $4^{\mathrm{a}}$ Vara Criminal de Duque de Caxias discordou do pedido do Parquet. Assim, determinou que os denunciados fossem colocados em liberdade provisória, independente de fiança, tendo em vista que mantê-los presos seria uma prática dispensável e indevida, uma vez que caso os denunciados fossem hipoteticamente condenados por tal prática receberiam penas mais brandas do que o regime fechado. ${ }^{18}$

Diante da irresignação da acusação, o Ministério Público interpôs um recurso em sentido estrito (autos $\mathrm{n}^{\circ}$ 0065502.27.2013.8.19.0000) contra Carlos Eduardo de Souza Pinto, Rosemere Aparecida Ferreira e Edilson Santos, visando a reforma da decisão recorrida. Tal recurso em 25 de fevereiro de 2014 foi unanimemente deferido pelos desembargadores da $4^{\mathrm{a}}$ Câmara Criminal, expedindo imediatamente mandados de prisão aos recorridos.

Tendo em vista o cerceamento da liberdade de ir e vir dos acusados, foi impetrado o remédio constitucional do Habeas Corpus no Superior Tribunal de Justiça (HC 290.341) visando a retomada de sua liberdade e a reforma da decisão proferida pelo Tribunal de Justiça do Rio de Janeiro. Entretanto, não foi concedida a ordem, razão ensejadora da propositura do Habeas Corpus impetrado no STF (HC 124.306). ${ }^{19}$

Nesse seguimento, o relator do HC 124.306 concedeu a ordem, inclusive aos corréus, abrangendo apenas a questão da liberdade de ir e vir dos pacientes, considerando que a liberdade dos acusados não estava gerando qualquer prejuízo ao processo. Assim, solicitou a vista dos autos ao Ministro Luís Roberto Barroso que teceu diversos comentários e posicionamentos de grande importância para o mundo jurídico acerca da descriminalização do aborto até o terceiro mês de gestação, questão do presente trabalho.

\footnotetext{
${ }^{18}$ BRASIL. Supremo Tribunal Federal. Habeas Corpus 124.306 Rio de Janeiro. Pág. 33. Disponível em: http://www.stf.jus.br/arquivo/cms/noticiaNoticiaStf/anexo/HC124306LRB.pdf. Acesso em: 28 de out. 2018

${ }^{19}$ Idem
} 
Primeiramente, o Ministro Barroso explicitou sobre a inconstitucionalidade da criminalização do aborto no primeiro trimestre, ressaltando os direitos fundamentais das mulheres violados, assim como a afronta ao Princípio da proporcionalidade. Para ele, em conformidade com o objetivo central do corrente estudo, a permissão do aborto, tem como intuito que o procedimento seja incomum e não coloque as mulheres em perigo, como segue:

(...) o aborto é uma prática que se deve procurar evitar, pelas complexidades físicas, psíquicas e morais que envolve. Por isso mesmo, é papel do Estado e da sociedade atuar nesse sentido, mediante oferta de educação sexual, distribuição de meios contraceptivos e amparo à mulher que deseje ter o filho e se encontre em circunstâncias adversas. Portanto, ao se afirmar aqui a incompatibilidade da criminalização com a Constituição, não se está a fazer a defesa da disseminação do procedimento. Pelo contrário, o que ser pretende é que ele seja raro e seguro.(... $)^{20}$

Desse modo, o objetivo central da descriminalização do aborto é reduzir o número de procedimentos inseguros e clandestinos, visando a garantia do Princípio da dignidade humana da mulher em toda sua extensão, com base na premissa de Kant de que todos os seres humanos devem ser considerados como um fim em si mesmo ${ }^{21}$, e não serem utilizados como meio, ou instrumento, para satisfazer interesses alheios, isto é, a mulher não pode ser operada como um apetrecho para dar vida a outrem, sem considerar seus anseios e valores. ${ }^{22}$

A Ministra Rosa Weber também deixou seu parecer que em questões de ética privada, como o aborto, o Estado deve se manter neutro ${ }^{23}$ , uma vez que os procedimentos abortivos fazem parte da esfera privada, moral e ética não devendo ser confundidos com a esfera da responsabilidade pública, inclusive com a atuação do Estado. ${ }^{24}$

Em seu voto concorrente a Ministra Rosa Weber, concordou com o posicionamento do Ministro Luís Roberto Barroso, inclusive com a questão da inconstitucionalidade dos arts. 124 a 126, e para fundamentar sua opinião, essa embasou seu entendimento no direito comparado e

\footnotetext{
${ }^{20} \mathrm{Idem}$

${ }^{21}$ TELES, Teresinha Inês. Direito ao aborto, democracia e constituição. Curitiba: Juruá, 2016. p. 83.

${ }^{22}$ BRASIL. Supremo Tribunal Federal. Habeas Corpus 124.306 Rio de Janeiro. Pág. 33. Disponível em: http://www.stf.jus.br/arquivo/cms/noticiaNoticiaStf/anexo/HC124306LRB.pdf. Acesso em: 28 de out. 2018

${ }^{23} \mathrm{Idem}$

${ }^{24}$ Idem
} 
também em dados estatísticos, deixando claro seu posicionamento acerca do aborto. ${ }^{25}$

Assim, apesar de ter sido afastada a prisão preventiva dos envolvidos, por uma questão meramente processual (ausência dos requisitos necessários), o citado Habeas Corpus, mesmo possuindo efeito apenas inter partes, foi de grande importância para a jurisprudência brasileira, posto que os ministros supracitados do STF demonstraram de forma clara seu posicionamento acerca da temática, acarretando além de um grande avanço com relação às liberdades das mulheres, um paradigma de peso para a evolução da autonomia procriativa.

\subsection{AÇÃO DE DESCUMPRIMENTO DE PRECEITO FUNDAMENTAL N. 442: ANDAMENTO DA ATUAL AÇÃO QUE VISA A DESCRIMINALIZAÇÃO DO ABORTO ATÉ A 12ª SEMANA}

O Partido Socialismo e Liberdade (PSOL) propôs a Arguição de Descumprimento de Preceito Fundamental 442, requerendo a descriminalização da interrupção da gestação até a $12^{\mathrm{a}}$ semana, em termos jurídicos, a não recepção parcial dos arts. 124 e 126 do Código Penal.

Tais artigos, como consta na petição inicial em questão, afrontam os princípios da dignidade da pessoa humana, da cidadania, da não discriminação, da vida, da igualdade, da proibição de tortura ou tratamento desumano ou degradante, da saúde e do planejamento familiar. ${ }^{26}$

O PSOL também argumentou que a descriminalização é de extrema urgência uma vez que ao impor às mulheres uma gravidez, essas são submetidas a grandes riscos físicos e psicológicos como também a uma persecução criminal desnecessária em que o Estado está invadindo a liberdade reprodutiva das mulheres, como estabelece em sua petição inicial:

Ainda que a taxa de prisão por aborto seja desprezível quando comparada ao universo de mulheres que realizaram aborto, não se pode argumentar ausência de efeitos nocivos da lei penal. Para além

\footnotetext{
${ }^{25}$ Idem

${ }^{26}$ BRASIL. Supremo Tribunal Federal. Arguição de Descumprimento de Preceito Fundamental 442. Disponível em: http://portal.stf.jus.br/processos/detalhe.asp?incidente $=5144865$. Acesso em: 11 fev. 2019. Página 1 da petição inicial.
} 
da persecução penal discriminatória imposta a decisões reprodutivas das mulheres, a criminalização do aborto amplia seus efeitos de morbimortalidade. Estudos recentes estimam que entre 8 e $18 \%$ de mortes maternas no mundo decorram de abortos inseguros, e estão concentradas em países pobres.10 No Brasil, a própria criminalização dificulta a produção de dados nacionais confiáveis sobre a mortalidade associada ao aborto inseguro, mas sabe-se que cerca de metade das mulheres que fez um aborto ilegal no país precisou ser internada. ${ }^{27}$

Ademais aos riscos da clandestinidade, cumpre registrar que o autor da referida ADPF também registrou em sua peça inicial os efeitos negativos que os dogmas religiosos podem gerar em uma sociedade, inclusive quanto à afronta aos direitos e liberdades das mulheres:

O dogmatismo religioso revela-se tão opressivo à liberdade das pessoas quanto a intolerância do Estado, pois ambos constituem meio de autoritária restrição à esfera de livre-arbítrio e de autodeterminação das pessoas, que hão de ser essencialmente livres na avaliação de questões pertinentes ao âmbito de seu foro íntimo, notadamente em temas do direito que assiste a mulher, seja o controle da sua própria sexualidade, e aí surge o tema dos direitos reprodutivos, seja sobre a matéria que confere o controle sobre a sua própria fecundidade. ${ }^{28}$

Demonstrando de forma clara e precisa que os dogmas religiosos são opressivos e ferem diretamente a autodeterminação das mulheres quanto a sua sexualidade. Nessa toada, é notório que em um Estado laico como o brasileiro, as decisões estatais, do Poder Legislativo, Executivo e Judiciário, deveriam se abster de fundamentações religiosas, o que lamentavelmente não ocorre na prática.

Nessa seara, faz-se necessário salientar os direitos fundamentais das mulheres que são violados com a criminalização da prática. Primeiramente a tipificação do aborto afronta a autonomia das gestantes, de decidir quando e se terão filhos, e a faculdade de planejar seu futuro, assim, privar as mulheres de suas escolhas e submetê-las a uma gravidez

\footnotetext{
${ }^{27}$ BRASIL. Supremo Tribunal Federal. Arguição de Descumprimento de Preceito Fundamental 442. Disponível em: http://portal.stf.jus.br/processos/detalhe.asp?incidente=5144865. Acesso em: 11 fev. 2019. p. 4 da petição inicial.

${ }^{28}$ Voto de Celso de Mello. (BRASIL. Supremo Tribunal Federal. Habeas Corpus n ${ }^{\circ} 84.025 / R F$, Relator: Min. Joaquim Barbosa. Brasília, DF, 04 de março de 2004. Diário da Justiça, Brasília, DF, 18 mar. 2004. Disponível em: http://redir.stf.jus.br/paginadorpub/paginador.jsp?docTP=AC\&docID=384874. Acesso em: 25 fev. 2017 apud BRASIL. Arguição de Descumprimento de Preceito Fundamental 442. Disponível em: http://portal.stf.jus.br/processos/detalhe.asp?incidente=5144865. Acesso em: 11 fev. 2019.
} 
indesejada viola a dignidade da pessoa humana e consequentemente sua autonomia e liberdades, como prescreve o Partido Socialismo e Liberdade em sua peça inicial.

O Partido requereu ainda a concessão de uma medida cautelar visando a suspensão das prisões em flagrantes, inquéritos policiais e andamentos de processos ou efeitos de decisões judiciais das mulheres que praticaram a interrupção da gestação até a $12^{\mathrm{a}}$ semana gestacional, demonstrando de forma clara e coesa a probabilidade do direito e o perigo de dano. Todavia, a ministra Rosa Weber indeferiu tal pedido argumentando que a problemática por ser extremamente polêmica, antes de qualquer decisão enseja um estudo e discussão prévia acerca dos diversos entendimentos. ${ }^{29}$

Nesse seguimento, muitas instituições pediram para ingressar na presente ADPF como amicus curie, algumas instituições favoráveis à descriminalização da prática abortiva até a $12^{\mathrm{a}}$ semana de gestação e outras desfavoráveis. ${ }^{30}$

Assim, considerando que o aborto é um tema que divide opiniões entre os religiosos, estudiosos do direito e defensores dos direitos humanos, a ministra Rosa Weber decidiu convocar uma audiência pública, para aprofundar a temática, que ocorreu nos dias 3 e 6 de agosto de $2018 .^{31}$

Tal audiência pública se deu de maneira extremamente proveitosa para o tema, posto que diversos expositores evidenciaram seus entendimentos, com o intuito de elucidarem aos ministros as causas e efeitos da ilegalidade e da descriminalização da prática abortiva. ${ }^{32}$

Sobretudo, a presente ADPF ainda está em andamento, aguardando os votos dos ministros. Espera-se que eles não violem os direitos fundamentais da mulher, a laicidade do Estado e se posicionem favoráveis a interrupção da gestação até a $12^{\mathrm{a}}$ semana, independente da motivação da mulher, colocando fim nos inúmeros abortamentos clandestinos que geram riscos demasiados para as mulheres, nas mortes maternas resultantes da prática abortiva e no estigma que a mulher é

\footnotetext{
${ }^{29}$ BRASIL. Supremo Tribunal Federal. Arguição de Descumprimento de Preceito Fundamental 442. Disponível em: http://portal.stf.jus.br/processos/detalhe.asp?incidente=5144865. Acesso em: 11 fev. 2019.

${ }^{30} \mathrm{Idem}$

${ }^{31}$ Idem

${ }^{32}$ Idem
} 
submetida, visando uma sociedade justa e igualitária quanto ao gênero feminino.

\section{CONSIDERAÇÕES FINAIS}

O presente trabalho buscou analisar a questão da prática abortiva no Brasil atualmente, averiguando principalmente a congruência existente entre os artigos que condenam o aborto da legislação penal e os direitos fundamentais das mulheres assegurados pela Constituição Federal, entre eles a dignidade da pessoa humana, a igualdade de gênero, a liberdade religiosa, tendo por base, ainda, a laicidade do Estado.

Ademais à análise do aborto no Brasil nos tempos atuais, se verificou o contexto histórico que compreende a prática abortiva no país, desde sua descoberta pelos portugueses, até os últimos andamentos sobre a temática no Supremo Tribunal Federal.

O tema do aborto é extremamente importante, posto que a prática abortiva é uma questão imensamente polêmica e atual, que afeta sobremaneira a vida das gestantes que gostariam e necessitam de realizar o procedimento.

Desse modo, a presente pesquisa também averiguou as consequências que a legislação punitiva do aborto tem na vida das mulheres que vivenciaram e vivenciam a problemática, concluindo-se que a criminalização não reduz as taxas abortivas, prova disso é o resultado obtido pela Pesquisa Nacional do Aborto de 2016, que verificou que quase uma em cada cinco mulheres até os 40 anos já realizou um abortamento. ${ }^{33}$

Diante de todo o exposto, conclui-se que a atual legislação punitiva brasileira do aborto no Brasil não reduz as taxas de abortamentos, tendo em vista que as mulheres que têm anseio pela realização do procedimento o fazem sendo ilegal ou não.

A criminalização oferece apenas dois caminhos às gestantes que almejam o aborto, o primeiro deles é levar a termo a gravidez indesejada, carregando por nove meses um ser em seu ventre, abdicando de seus sonhos e seu projeto de vida, o que viola prontamente sua dignidade

\footnotetext{
${ }^{33}$ Pesquisa Nacional de Aborto 2016. Disponível em: <http://www.scielo.br/scielo.php?pid=S1413$1232017000200653 \&$ script=sci_abstract\&tlng=pt. $>$ Acesso em: 05.05.2019.
} 
humana, autonomia procriativa, liberdade de consciência e de crença e corrobora com as desigualdades de gênero, sociais e raciais.

O segundo caminho é a submissão das mulheres a procedimentos precários, inseguros e insalubres que em muitos casos ocasionam sérias complicações médicas, como hemorragias, infecções, perfuração do útero e até a mortalidade materna, que possui índices altíssimos no país, sendo o direito ao aborto uma questão de saúde pública.

Ademais à consequência direta da criminalização da prática abortiva, há que se falar também que a proibição do aborto mantém o estereótipo da mulher mãe e dona de casa, uma vez que a realização do referido procedimento seria um desvio no "destino" da mulher, o que viola sobremaneira o direito à igualdade de gênero.

Por isso, faz-se necessária a revisão da legislação punitiva brasileira, para que se garanta às mulheres a autodeterminação no que se refere a sua sexualidade e seu planejamento de vida e consequentemente o acesso a um procedimento abortivo, sem quaisquer restrições, realizado por um médico habilitado, em uma clínica segura e em conformidade com as normas da medicina, garantindo, assim, as gestantes o direito fundamental a autonomia procriativa e sua efetiva dignidade da pessoa humana.

\section{REFERÊNCIAS}

BARROSO, Luís Roberto. A dignidade da pessoa humana no direito constitucional contemporâneo: natureza jurídica, conteúdos mínimos e critérios de aplicação. Disponível em: < https://www.luisrobertobarroso.com.br/wpcontent/uploads/2010/12/Dignidade_texto-base_11dez2010.pdf >. Acesso em: 13.05.2019.

BITENCOURT, Cezar Roberto. Tratado de direito penal, 2: parte especial: dos crimes contra a pessoa.12. ed. rev. e ampl. São Paulo: Saraiva, 2012.

BRASIL. Supremo Tribunal Federal. Arguição de Descumprimento de Preceito Fundamental 442. Disponível em: < http://portal.stf.jus.br/processos/detalhe.asp?incidente=5144865 > Acesso em: 11 fev. 2019. Página 1 da petição inicial.

BRASIL. Supremo Tribunal Federal. Habeas Corpus 124.306 Rio de Janeiro. Disponível em: http://www.stf.jus.br/arquivo/cms/noticiaNoticiaStf/anexo/HC124306LRB.pdf. Acesso em: 28 de out. 2018 
CASTILHO, Ricardo. Direitos humanos. 5. ed. São Paulo: Saraiva, 2015.

HUNGRIA, Nélson. Comentários ao Código Penal. Volume 5. 4. ed. Rio de Janeiro: Forense 1958.

KREUZ, Letícia Regina Camargo. Domínio do corpo: O aborto entre leis e juízes. Curitiba: Íthala, 2018. p. 31

Pesquisa Nacional de Aborto 2016. Disponível em:

<http://www.scielo.br/scielo.php?pid=S1413-

81232017000200653\&script=sci_abstract\&tlng=pt.> Acesso em: 05.05.2019.

TAVARES, André Ramos. Curso de Direito Constitucional. 8. ed. São Paulo: Editora Saraiva, 2010.

TELES, Teresinha Inês. Direito ao aborto, democracia e constituição. Curitiba: Juruá, 2016. 